\title{
Optimal Liquid Spawn Conditions and Grain Medium Enhanced Hispidin Production by Phellinus linteus in Solid-State Fermentation
}

Chih-Hung Liang

Tunghai University

Chiu-Yeh Wu

Chung Chou Junior College of Technology and Commerce: Chung Chou University of Science and Technology

Chin-Hao Ou

Da-Yeh Institute of Technology: Dayeh University

Zeng-Chin Liang ( $\nabla$ zcliang@mail.dyu.edu.tw)

Da-Yeh University https://orcid.org/0000-0003-1867-1227

\section{Research Article}

Keywords: Phellinus, Solid-state fermentation, Hispidin, Spawn, Inoculum rate

Posted Date: July 7th, 2021

DOl: https://doi.org/10.21203/rs.3.rs-665841/v1

License: (9) This work is licensed under a Creative Commons Attribution 4.0 International License. Read Full License 


\section{Abstract}

This study aimed to screen a highest hispidin production of strain from 12 strains of Phellinus, and to evaluate the effects of liquid spawn conditions and grain medium on this strain's hispidin production levels after solid-state fermentation. Results showed that the $P$. linteus 04 led to the highest hispidin production, this strain was then selected to elucidate the optimal liquid spawn conditions and grain medium for hispidin production. Various liquid spawn conditions were evaluated, and the highest hispidin yield, specific productivity of hispidin, and total content of hispidin were found to be optimal at 1 week of liquid spawn age, cultured with potato dextrose borth, and using $10 \%$ inoculum rate, with each condition resulting to $0.350,0.325$, and $0.328 \mathrm{mg} / \mathrm{g}$ dry weight of mycelium, $0.352,0.251$, and $0.249 \mu \mathrm{g} / \mathrm{mg} \mathrm{week}^{-1}$ specific productivity, $57.90,60.23$, and $61.77 \mathrm{mg} / \mathrm{kg}$ dry weight of brown rice medium, respectively. These liquid spawn conditions were then used to determine the appropriate grain medium for hispidin production. The highest hispidin yield and total content of hispidin were observed in pearl barley which resulted in $1.107 \mathrm{mg} / \mathrm{g}$ dry weight of mycelium and $199.76 \mathrm{mg} / \mathrm{kg}$ dry weight of pearl barley, which led to results that were 4.73-fold and 5.35-fold higher than those of control (brown rice medium). Overall, this study shows that $P$. linteus hispidin production can be enhanced by solid-state fermentation using optimal liquid spawn conditions and the appropriate grain medium.

\section{Introduction}

Several medicinal mushrooms belonging to the genus Phellinus possess a variety of biological activities, including anti-tumor [1,2], anti-cancer [3,4], immunomodulatory [3], anti-diabetic [3,5], hypoglycemic effect [6], anti-inflammatory [3,7], anti-oxidant [3,8], and antibacterial activity [9].

Recently, a number of bioactive substances have been isolated from the genus Phellinus, these substances include hispidin, hispolon, and other styrylpyrone- type compounds [10]. Hispidin, a yellow polyphenol pigment of secondary metabolites, was mainly isolated from the cultural broth, mycelium, or fruiting body of Phellinus strains. This compound exhibits a broad spectrum of biological activities, including strong anti-oxidant [11,12], anti-cancer [13,14], anti-inflammatory [15,16], anti-viral [17], antiobesity [18], and anti-dementia [19] activities.

The fruiting body of Phellinus is scarcely found in nature; moreover it is expensive as it can be used as raw material for medicine. A long period of time is necessary to cultivate the fruiting body of Phellinus in order to obtain hispidin. Compared to submerged fermentation, the process of solid-state fermentation has led to higher yields and productivities, as well as to improve product characteristics and lower costs due to the utilization of grains or agricultural residues [20]. Recent studies have shown that some active compounds in cereals become enhanced when fermented by mushrooms [21], and that these compounds possess some biological activities such as immunomodulatory effect [22], anti-inflammatory effect [23], and the ability of prevent colon cancer metastasis [24]. 
Little information is available on whether or not altering liquid spawn conditions and grain media could affect hispidin production by the solid-state fermentation of Phellinus strains. Thus, in this study hispidin production of 12 strains of Phellinus were evaluated in fermented grains through solid-state fermentation; moreover, this study aimed to investigate the effects of liquid spawn conditions such as spawn age, liquid spawn culture medium, and inoculum rate, and grain media on hispidin production.

\section{Materials And Methods}

\section{Materials}

Potato dextrose agar, potato dextrose broth, yeast extract and malt extract were purchased from Himedia Laboratories (Mumbai, India). Brown rice was purchased from Wu-Wang Grain Co. Ltd. (Chiayi, Taiwan). Millet, black rice, wheat, buckwheat, pearl barley, oat and adlay were purchased from a local market in Yuanlin (Changhua, Taiwan). Hispidin and ergosterol were purchased from Sigma-Aldrich Chemical Co. (St. Louis, MO, USA). All other chemical reagents were analytical grade.

\section{Microorganisms}

Phellinus apiahynus BCRC35468, P. igniarius BCRC 35308, P. pachyphloeus BCRC MU30300 and Phellinus sp. BCRC 36900 were purchased from the Bioresource Collection and Research Center, Food Industry Research and Development Institute, Hsinchu, Taiwan. Phellinus sp. L was isolated from the fruiting body (obtained from Nantou, Taiwan) and was identified by the upper Institute. P. linteus 03, $P$. linteus 04, P. linteus 06, P. linteus Youhao, $P$. linteus Wang, P. linteus 85105 and $P$. linteus Zhejiang were stored in our laboratories and identified by Tri-l Biotech. Inc., Taichung, Taiwan. The symbols and sources of these twelve strains are presented in Table 1.

Samples of each Phellinus strains were grown on potato dextrose agar (PDA, $200 \mathrm{~g} / \mathrm{L}$ diced potatoes; 20 $\mathrm{g} / \mathrm{L}$ glucose; $15 \mathrm{~g} / \mathrm{L}$ agar) medium at $25^{\circ} \mathrm{C}$ for regular subculture, and were maintained on PDA slants at $4^{\circ} \mathrm{C}$ for a maximum of 3 months.

\section{Liquid spawn preparation}

Phellinus samples were initially grown on PDA medium at $25^{\circ} \mathrm{C}$, and the mycelium was harvested after 14 days. Two mycelial agar discs $(1 \mathrm{~cm} \times 1 \mathrm{~cm})$ were obtained using a sterilized knife and transferred into the spawn media, which contained $100 \mathrm{~mL}$ of PDB (PDB, $200 \mathrm{~g} / \mathrm{L}$ diced potatoes; $20 \mathrm{~g} / \mathrm{L}$ glucose) in 250 $\mathrm{mL}$ flasks; then, they were incubated in an orbital shaking incubator at $120 \mathrm{rpm}$ at $25^{\circ} \mathrm{C}$ for 1 week. The liquid products of the mycelial culture were used directly as liquid spawn.

\section{Basal grain medium preparation, inoculation, and incubation}

The basal grain medium used was brown rice, which was prepared by filling wide-neck glass bottles with $60 \mathrm{~g}$ of grains and $75 \mathrm{~mL}$ of water; these were autoclaved at $121^{\circ} \mathrm{C}$ for $30 \mathrm{~min}$. After the brown rice medium was cooled to room temperature, these were inoculated with $6 \mathrm{~mL}$ of liquid spawn. 
Inoculated brown rice media were kept in a spawn running room at $25^{\circ} \mathrm{C}$ under dark conditions. Samples were taken every week to determine hispidin and ergosterol contents during the 8 weeks of incubation.

\section{Effect of liquid spawn conditions and grain media for hispidin production}

Our previous study showed that after screening 12 Phellinus strains, $P$. linteus 04 led to the highest hispidin yield. Various parameters were then selected to examine the effects of liquid spawn conditions, such as spawn age, liquid spawn culture medium, inoculum rate, and grain media on the hispidin production of $P$. linteus 04 . Each factor was analyzed individually as described below. Samples were taken every week to determine hispidin and ergosterol contents during the 8 weeks of incubation.

\section{Effect of spawn age}

To determine the optimal spawn age for hispidin production, $P$. linteus 04 was cultivated in brown rice media inoculated with different ages of liquid spawn (1,2, and 3 weeks). The different ages of liquid spawn were cultured as previously described.

\section{Effect of liquid spawn culture medium}

To evaluate the best liquid spawn culture medium for hispidin production, cultured in potato dextrose broth (PDB), yeast extract glucose broth (YG, $3 \mathrm{~g} / \mathrm{L}$ Yeast extract; $3 \mathrm{~g} / \mathrm{L}$ malt extract; $10 \mathrm{~g} / \mathrm{L} \mathrm{glucose;} 5 \mathrm{~g} / \mathrm{L}$ peptone), and malt extract broth (ME, $20 \mathrm{~g} / \mathrm{L}$ malt extract; $20 \mathrm{~g} / \mathrm{L}$ glucose; $1 \mathrm{~g} / \mathrm{L}$ peptone) medium of $P$. linteus 04 liquid spawn for 1 week of incubation were inoculated on brown rice media, respectively.

\section{Effect of inoculum rate}

To evaluate the optimal inoculum rate for hispidin production, $P$. linteus 04 was cultivated in brown rice media inoculated with different volumes of inoculum: 3 (5\% of inoculum rate, v/w), 6 (10\% of inoculum rate, $\mathrm{v} / \mathrm{w})$, or $9(15 \%$ of inoculum rate, $\mathrm{v} / \mathrm{w}) \mathrm{mL} /$ bottle were used.

\section{Effect of grain media}

The basal brown rice grain medium was used as control, and seven different grain media (millet, black rice, wheat, buckwheat, pearl barley, oat, and adlay) were prepared by filling wide-neck glass bottles with $60 \mathrm{~g}$ of grains and $75 \mathrm{~mL}$ of water; these bottles were autoclaved at $121^{\circ} \mathrm{C}$ for $30 \mathrm{~min}$. Grain media fermentation was carried out under the following conditions: liquid spawn was cultured for 1 week, inoculated with $6 \mathrm{~mL}$ of inoculum, and cultured with liquid spawn in PDB. Cultivations were maintained for 8 weeks after the liquid spawn inoculation. Samples were taken every week to determine hispidin and ergosterol contents during the 8 weeks of incubation.

\section{Samples analysis}

Fermented grain media from the different treatments were harvested and then dried at $60^{\circ} \mathrm{C}$ to a constant weight, after which they were ground into powder using a grinder. Sample powders were then stored in a 
desiccator until extract preparation.

\section{Determination of ergosterol content}

Ergosterol, a major fungal sterol, can indicate the mycelia levels in fungi [25]. In this study, ergosterol was used as a measure of the growth of Phellinus strains in grain media. Ergosterol

extraction from fermented grain media was performed according to the method of Matcham et al. [26] with some modifications. One gram of dry fermented grain powder was vortexed with $4 \mathrm{~mL}$ of hexane for $90 \mathrm{~s}$, centrifuged at 1,310 $\times \mathrm{g}$ for $10 \mathrm{~min}$, and the supernatant (hexane phase) was transferred into a vial. The residue was further extracted twice with $4 \mathrm{~mL}$ of hexane. The hexane phases were collected and dried by evaporation under a vacuum at $40^{\circ} \mathrm{C}$. The extract was then dissolved in $5 \mathrm{~mL}$ of methanol and filtered through a $0.45-\mu \mathrm{m}$ filter prior to high-performance liquid chromatography (HPLC) analysis.

Ergosterol content was analyzed using HPLC (PU-2080 Plus, JASCO, Japan) with a Kinetex 5 $\mu$ C18 100A column (Phenomenex, Torrance, CA, USA), and the flow rate of the mobile phase consisting of methanol was set to $1.2 \mathrm{~mL} / \mathrm{min}$. Detection was carried out using a refractive index detector (Shodex RI-71, Showa Denko K.K., Kawasaki, Japan). The eluent was analyzed at $282 \mathrm{~nm}$ using a UV/Visible Detector (Shimadzu SPA-20A; Shimadzu, Sci. Inst., Kyoto, Japan). Working solution of ergosterol was freshly prepared. Quantification was based on the UV signal response of ergosterol using the external standard method and a standard calibration curve were generated with six points with concentrations of $0,25,50$, 100,200 , and $400 \mu \mathrm{g} / \mathrm{mL}$.

\section{Determination of hispidin content}

Hispidin extraction from fermented grain media was conducted according to the method of Lee and Yun [27], with some modifications. In brief, 0.2 grams of dry fermented grain powder was extracted with $10 \mathrm{~mL} 100 \%$ of methanol under an ultrasonic cleaner (DC200H, DELTA Ultrasonic Co., Ltd., Taiwan) for $60 \mathrm{~min}$.

The supernatant was separated by centrifugation, which was set to $18,400 \times g$ for $10 \mathrm{~min}$; this was then filtered through a $0.45-\mu \mathrm{m}$ filter. The filtrate was then assayed for hispidin content. To measure hispidin, the HPLC system was equipped with a Kinetex $5 \mu$ C18 100A column $(250 \times 4.6 \mathrm{~mm}, 5$ micron, Phenomenex, Torrance, CA, USA). Methanol was used as the mobile phase, and flow rate was set at $1.2 \mathrm{~mL} / \mathrm{min}$. The eluent was analyzed at $254 \mathrm{~nm}$ using a UV/Visible Detector (Shimadzu SPA-20A; Shimadzu, Sci. Inst., Kyoto, Japan). The concentration of hispidin stock solution was $1000 \mu \mathrm{g} / \mathrm{mL}$, and stored at $-40^{\circ} \mathrm{C}$. Quantification was based on the UV signal response of hispidin using the external standard method and a standard calibration curve was prepared using $5-50 \mu \mathrm{g} / \mathrm{mL}$ of hispidin.

The specific productivity of hispidin was calculated as: hispidin yield [hispidin content (mg) / mycelia (g)] $\div$ biomass [mycelia (mg) / medium (g)] $\div$ time (week).

Total hispidin content was calculated as: biomass [mycelia $(\mathrm{mg}) /$ medium $(\mathrm{g})$ ] $\times$ hispidin yield [hispidin content (mg) / mycelia (g)]. 


\section{Statistical analysis}

Data are presented as the mean \pm standard deviation $(n=3)$. Differences between the means of individual groups were assessed using one-way ANOVA with Duncan's multiple-range test.

\section{Results And Discussion}

\section{Screening of high hispidin production of Phellinus strain}

Twelve strains of Phellinus were screened for high hispidin production; the strains used were as follows: 1 strain of $P$. igniarius, 1 strain of $P$. apiahynus, 1 strain of $P$. pachyphloeus, 8 strains of $P$. linteus and 2 strains of $P$. sp., respectively. Our results showed that for most tested strains, higher hispidin production was observed at 6 or 8 weeks of fermentation (Table 2). P. linteus 04 had highest hispidin production, followed by $P$. linteus 03 and $P$. linteus $L$, with their corresponding hispidin yields being 0.395 , 0.369 , and $0.354 \mathrm{mg} / \mathrm{g}$ dry weight of mycelium, respectively. However, the hispidin yields of $P$. linteus 04 and $P$. linteus 03 were not significantly different $(P<0.05)$. The highest specific productivity of hispidin was observed in $P$. linteus $L$, followed by $P$. linteus 04 and $P$. linteus 03 , with the corresponding specific productivities being $0.396,0.371$, and $0.326 \mu \mathrm{g} / \mathrm{mg} \mathrm{week}^{-1}$, respectively. The highest total content of hispidin in brown rice medium was observed in $P$. linteus $04(70.05 \mathrm{mg} / \mathrm{kg}$ dry weight of brown rice medium) at 6 weeks of incubation, followed by $P$. linteus $03(69.65 \mathrm{mg} / \mathrm{kg}$ dry weight of brown rice medium) and $P$. linteus $L(63.37 \mathrm{mg} / \mathrm{kg}$ dry weight of brown rice medium) at 6 weeks and 5 weeks of fermentation time, respectively (Fig. 1). The optimal strain for hispidin production was therefore $P$. linteus 04 , due to its higher hispidin yield and total hispidin content compared to the other strains. As such, $P$. linteus 04 was further evaluated to determine the optimal liquid spawn conditions and grain medium for hispidin production.

In this study, twelve strains of Phellinus were screened to determine which strain led to the highest hispidin yield. P. linteus 04 was the strain with the highest hispidin production, followed by $P$. linteus 03 and $P$. linteus $\mathrm{L}$. The respective hispidin yields of these three strains at their peak hispidin production time were 5.41-fold, 5.05-fold, and 4.85-fold higher than the yield of $P$. linteus 04 grown on liquid cultures using potato dextrose broth medium fermented for 14 days $(0.073 \pm 0.005 \mathrm{mg} / \mathrm{g}$ dry weight of mycelium; data not shown on the table). According to these results, hispidin yield of $P$. linteus produced by solid state fermentation is higher than the yield from liquid state fermentation.

All the Phellinus strains were able to grow on brown rice medium except for $P$. apiahynus. Mycelial color ranged from greyish white to yellow, but hispidin yields were not correlated to mycelial color, even if hispidin is a yellow pigment. $P$. linteus strains could produce hispidin; however, $P$. apiahynus, $P$. pachyphloeus, and $P$. sp. were unable to do so. Therefore, we found that not all Phellinus strains are able to produce hispidin. The result is in accordance with studies that indicate hispidin is present in the genera Phellinus and Inonotus [10,28], such as $P$. linteus $[3,11,12,29]$ and $I$. xeranticus $[12,29]$. Though all $P$. linteus strains could produce hispidin, differences exist between different $P$. linteus strains. The 
hispidin yields of some of the tested strains of $P$. linteus, such as $P$. linteus $06, P$. linteus Youhao, $P$. linteus Wang, and $P$. linteus 85105 , led to yields below $0.2 \mathrm{mg} / \mathrm{g}$ dry weight of mycelium; no prior studies have reported about these results.

At 8 weeks of fermentation, hispidin yield of the hispidin-producing strains were gradually enhanced as fermentation time increased; however, when hispidin yield reached its maximum level, it then rapidly dropped for most of the tested strains. Our results were similar to those of Park et al. [11] who reported that the highest $P$. linteus hispidin yield using liquid state fermentation $(2.5 \mathrm{mg} / \mathrm{mL})$ was observed at 10 days of incubation, and then decreased to near $0 \mathrm{mg} / \mathrm{mL}$ at 18 days of incubation. This showed that hispidin might be polymerized by the enzymatic oxidative coupling reaction after the 12th day [11].

\section{Effect of spawn age}

Fig. 2 showed that three different spawn ages influenced mycelial growth and hispidin production in brown rice fermented by $P$. linteus 04 during fermentation. The highest hispidin yield, specific productivity of hispidin, and total content of hispidin were observed at 1 week of liquid spawn age at 6 weeks of fermentation time which indicated significantly higher $(P<0.05)$ than those of 2 and 3 weeks of liquid spawn age, with the corresponding results being $0.350 \mathrm{mg} / \mathrm{g}$ dry weight of mycelium, $0.352 \mu \mathrm{g} / \mathrm{mg}$ week

${ }^{1}$ specific productivity, and $57.90 \mathrm{mg} / \mathrm{kg}$ dry weight of brown rice medium, respectively. These were followed by the use of 2 and 3 weeks of liquid spawn age together with 6 weeks of fermentation, with the corresponding results for hispidin yield being 0.219 and $0.209 \mathrm{mg} / \mathrm{g}$ dry weight of mycelium, specific productivity at 0.215 and $0.199 \mu \mathrm{g} / \mathrm{mg} \mathrm{week}^{-1}$, and total hispidin content at 37.26 and $36.63 \mathrm{mg} / \mathrm{kg}$ dry weight, respectively.

\section{Effect of liquid spawn culture medium}

Fig. 3 showed that liquid spawn grown in three different culture media influenced mycelial growth and hispidin production in brown rice fermented by $P$. linteus 04 during fermentation. The highest hispidin yield, specific productivity of hispidin, and total hispidin content were observed in cultures with liquid spawn grown in potato dextrose broth at 7 weeks of fermentation, which resulted in $0.325 \mathrm{mg} / \mathrm{g}$ dry weight of mycelium, $0.251 \mu \mathrm{g} / \mathrm{mg}$ week $^{-1}$ specific productivity, and $60.23 \mathrm{mg} / \mathrm{kg}$ dry weight of brown rice medium. This was followed by cultures with liquid spawn grown in yeast extract glucose broth at 8 weeks of fermentation, resulting in $0.238 \mathrm{mg} / \mathrm{g}$ dry weight of mycelium, $0.167 \mu \mathrm{g} / \mathrm{mg}$ week $^{-1}$ specific productivity, and $42.42 \mathrm{mg} / \mathrm{kg}$ dry weight of brown rice medium. The third highest was observed in cultures with liquid spawn grown in malt extract broth at 7 weeks of fermentation, resulting in $0.191 \mathrm{mg} / \mathrm{g}$ dry weight of mycelium, $0.165 \mu \mathrm{g} / \mathrm{mg} \mathrm{week}^{-1}$ specific productivity, and $31.56 \mathrm{mg} / \mathrm{kg}$ dry weight of brown rice medium.

\section{Effect of inoculum rate}


Fig. 4 showed that three different liquid spawn inoculum rates influenced mycelial growth and hispidin production in brown rice fermented by $P$. linteus 04 during fermentation. The highest hispidin yield, specific productivity of hispidin, and total hispidin content were observed at an inoculum rate of $10 \%$ at 7 weeks of fermentation which indicated significantly higher $(P<0.05)$ than those of inoculum rate of 5 and $15 \%$, resulting in $0.328 \mathrm{mg} / \mathrm{g}$ dry weight of mycelium, $0.249 \mu \mathrm{g} / \mathrm{mg}$ week $^{-1}$ specific productivity, and $61.77 \mathrm{mg} / \mathrm{kg}$ dry weight of brown rice medium. This was followed by an inoculum rate of $5 \%$ at 7 weeks of fermentation, which led to $0.219 \mathrm{mg} / \mathrm{g}$ dry weight of mycelium, $0.168 \mu \mathrm{g} / \mathrm{mg}$ week $^{-1}$ specific productivity, and $40.70 \mathrm{mg} / \mathrm{kg}$ dry weight of brown rice medium. Third highest was the use of $15 \%$ inoculum rate at 7 weeks of fermentation, resulting in $0.149 \mathrm{mg} / \mathrm{g} \mathrm{dry}$ weight of mycelium, $0.106 \mu \mathrm{g} / \mathrm{mg}$ week $^{-1}$ specific productivity, and $29.96 \mathrm{mg} / \mathrm{kg}$ dry weight of brown rice medium.

\section{Effect of grain media}

According to our results, optimal liquid spawn conditions are as follows: 1 week of liquid spawn age, culturing in potato dextrose broth, and the use of $10 \%$ inoculum rate. These liquid spawn conditions were then used to determine an appropriate grain medium for hispidin production.

Fig. 5 shows mycelial growth and hispidin production using different types of grain media fermented by $P$. linteus 04 . Eight different grain media were tested, and brown rice medium was used as a control. The medium that led to the highest hispidin yield, specific productivity of hispidin, and total hispidin content (Table 3) was pearl barley medium at 6 weeks of fermentation, resulting in 1.107 $\mathrm{mg} / \mathrm{g}$ dry weight of mycelium, $1.022 \mu \mathrm{g} / \mathrm{mg}$ week $^{-1}$ specific productivity, and $199.76 \mathrm{mg} / \mathrm{kg}$ dry weight of pearl barley medium. This is followed by black rice medium at 6 weeks of fermentation, resulting in $0.819 \mathrm{mg} / \mathrm{g}$ dry weight of mycelium, $1.236 \mu \mathrm{g} / \mathrm{mg}$ week $^{-1}$ specific productivity, and $90.43 \mathrm{mg} / \mathrm{kg}$ dry weight of black rice medium. Third was adlay medium at 7 weeks of fermentation, resulting in 0.815 $\mathrm{mg} / \mathrm{g}$ dry weight of mycelium, $0.644 \mu \mathrm{g} / \mathrm{mg}$ week $^{-1}$ specific productivity, and $147.28 \mathrm{mg} / \mathrm{kg}$ dry weight of adlay medium.

The highest hispidin yield, specific productivity of hispidin, and total hispidin content for grain media fermented by $P$. linteus 04 was observed in the pearl barley medium, which led to results that were 4.73fold, 4.17-fold, and 5.35-fold higher than those of control (brown rice medium), respectively. This was followed by black rice medium, with results that were 3.50-fold, 5.04-fold, and 2.42-fold higher than those of control. Adlay medium was third highest, with results that were 3.48-fold, 2.63-fold, and 3.95fold higher than those of control, respectively. This shows that these grain media are appropriate for hispidin production via $P$. linteus 04 fermentation. Notably, hispidin yield, specific productivity of hispidin, and total hispidin content reached their maximum levels at 6 weeks of fermentation in the pearl barley medium. Although hispidin yield decreased to $0.599 \mathrm{mg} / \mathrm{g}$ dry weight of mycelium and the specific productivity of hispidin decreased to $0.437 \mu \mathrm{g} / \mathrm{mg}$ week $^{-1}$ at 7 weeks of fermentation, total hispidin content was found to be $117.3 \mathrm{mg} / \mathrm{kg}$ dry weight of the pearl barley medium, which is higher than that of brown rice, millet, black rice, wheat, buckwheat, and oat media (Table 3). These indicate 
that pearl barley is an appropriate alternative medium as it may steadily induce hispidin production. Our results are in accordance with the work of Martins et al. [20], which stated that changes in phenolic acid profiles due to fermentation strongly depend on the type of substrate, fungus used, and fermentation conditions.

Some grains fermented by $P$. linteus exhibit various biological activities. Germinated brown rice fermented by $P$. linteus was reported to possess immunomodulatory activity [22], anti-inflammatory activity [23], and the ability to suppress metastasis and induce apoptosis of colon cancer cells [24]. Adlay and rice fermented by $P$. linteus could significantly enhance the total content of ascorbic acid, polyphenols, and flavonoids when extracted using hot water [30](Liang et al., 2009). In our study, grains fermented by $P$. linteus could enhance total hispidin content. We also demonstrated that solid state fermentation can potentially improve the biological functionalities of compounds in various grains [20]. Therefore, whether or not $P$. linteus-fermented grain products containing hispidin possess improved biological activity is worth to investigating in the future.

\section{Conclusion}

In this study, we screened several Phellinus strains and found that $P$. linteus 04 is a strain that exhibited a high hispidin yields, hispidin specific productivity, and total hispidin content when fermented in brown rice. We also concluded that optimal $P$. linteus 04 hispidin production conditions were as follows: 1 week of liquid spawn age, the use of potato dextrose broth inoculation medium, and the use of $10 \%$ inoculum rate. Moreover, using these liquid spawn conditions, 8 grains were investigated to find an alternative medium for hispidin production, and our results showed that pearl barley serves as an appropriate alternative medium.

\section{Declarations}

\section{Acknowledgement}

This work was supported by research grants from the Ministry of Science and Technology of the Republic of China (MOST106-2221-E-212-011).

Ethics Approval Not applicable.

Consent to Participate The authors give their consent to participate in this article.

Consent to Publish The authors give their consent to publish this article.

Authors Contributions Dr. Chih-Hung Liang carried out the analytical experiments, discussed the results, and wrote the analytical methods. Dr. Chiu-Yeh Wu carried out the analytical experiments and discussed the results. Mr. Chin-Hao Ou carried out the experiments. Dr. Zeng-Chin Liang conceived, planned the experiments and wrote the manuscript. All authors read and approved the final manuscript. 
Funding Not applicable.

Competing Interests The authors declare no competing interests.

Availability of Data and Materials Not applicable.

\section{References}

1. Song, Y. S., Kim, S. H., Sa, J. H., Jin, C., Lim, C. J., \& Park, E. H. (2003). Anti-angiogenic, antioxidant and xanthine oxidase inhibition activities of the mushroom Phellinus linteus. Journal of Ethnopharmacology, 88, 113-116.

2. Mei, Y., Zhu, H., Hu, Q., Liu, Y. Y., Zhao, S., Peng, N., \& Liang, Y. X. (2015). A novel polysaccharide from mycelia of cultured Phellinus linteus displays antitumor activity through apoptosis. Carbohydrate Polymers, 124, 90-97.

3. Chen, H., Tian, T., Miao, H., \& Zhao, Y. Y. (2016). Traditional uses, fermentation, phytochemistry and pharmacology of Phellinus linteus: A review. Fitoterapia, 113, 6-26.

4. Shon, Y. H., \& Nam, K. S. (2001). Antimutagenicity and induction of anticarcinogenic phase Il enzymes by basidiomycetes. Journal of Ethnopharmacology, 77, 103-109.

5. Yamac, M., Zeytinoglu, M., Senturk, H., Kartkaya, K., Kanbak, G., Bayramoglu, G., Oglakci, A., \& Griensven, L.J.L.D.V. (2016). Effects of black hoof medicinal mushroom, Phellinus linteus (Agaricomycetes), polysaccharide extract in streptozotocin-induced diabetic rats. International Journal of Medicinal Mushrooms, 18, 301-311.

6. Zhao, C., Liao, Z., Wu, X., Liu, Y., Liu, X., Lin, Z., Huang, Y., \& Liu, B. (2014). Isolation, purification, and structural features of a polysaccharide from Phellinus linteus and its hypoglycemic effect in alloxaninduced diabetic mice. Journal of Food Science, 79, H1002-1010.

7. Kim, S. H., Song, Y. S., Kim, S. K., Kim, B. C., Lim, C. J., \& Park, E. H. (2004). Anti-inflammatory and related pharmacological activities of the $\mathrm{n}-\mathrm{BuOH}$ subfraction of mushroom Phellinus linteus. Journal of Ethnopharmacology, 93, 141-146.

8. Shon, M. Y., Kim, T. H., \& Sung, N. J. (2003). Antioxidants and free radical scavenging activity of Phellinus baumii (Phellinus of Hymenochaetaceae) extract. Food Chemistry, 82, 593-597.

9. Sittiwet, C., \& Puangpronpitag, D. (2008). Antibacterial activity of Phellinus gilvus aqueous extract. International Journal of Pharmaceutics, 4, 500-502.

10. Lee, I. K., \& Yun, B. S. (2011). Styrylpyrone-class compounds from medicinal fungi Phellinus and Inonotus spp., and their medicinal importance. The Journal of Antibiotics, 64, 349-359. 
11. Park, I. H., Chung, S. K., Lee, K. B., Yoo, Y. C., Kim, S. K., Kim, G. S., \& Song, K. S. (2004). An antioxidant hispidin from the mycelial cultures of Phellinus linteus. Archives of Pharmacal Research, 27, 615-618.

12. Jung, J. Y., Lee, I. K., Seok, S. J., Lee, H. J., Kim, Y. H., \& Yun, B.S. (2008). Antioxidant polyphenols from the mycelial culture of the medicinal fungi Inonotus Xeranticus and Phellinus linteus. Journal of Applied Microbiology, 104, 1824-1832.

13. Gonindard, C., Bergonzi, C., Denier, C., Sergheraert, C., Klaebe, A., Chavant, L., \& Hollande, E. (1997). Synthetic hispidin, a PKC inhibitor, is more cytotoxic toward cancer cells than normal cells in vitro. Cell Biology and Toxicology, 13, 141-153.

14. Lim, J. H., Lee, Y. M., Park, S. R., Kim, D. H., \& Lim, B. O. (2014). Anticancer activity of hispidin via reactive oxygen species-mediated apoptosis in colon cancer cells. Anticancer Research, 34, 4087-4093.

15. Kim, B. C., Jeon,W. K., Hong, H. Y., Jeon, K. B., Hahn, J. H., Kim, Y. M., Numazawa, S., Yosida, T., Park, E. H., \& Lim, C. J. (2007). The anti-inflammatory activity of Phellinus linteus (Berk. \& M.A. Curt.) is mediated through the PKCdelta/Nrf2/ARE signaling to up-regulation of heme oxygenase-1. Journal of Ethnopharmacology, 113, 240-247.

16. Kim, H. G., Yoon, D. H., Lee, W. H., Han, S. K., Shrestha, B., Kim, C. H., Lim, M. H., Chang, W., Lim, S., \& Choi, S. (2007). Phellinus linteus inhibits inflammatory mediators by suppressing redox-based NF-kappaB and MAPKs activation in lipopolysaccharide-induced RAW 264.7 macrophage. Journal of Ethnopharmacology, 114, 307-315.

17. Awadh Ali, N. A., Nothana, R. A., Lesnau, A., Pilgrim, H., \& Lindequist, U. (2003). Antiviral activity of Inonotus hispidus. Fitoterapia, 74, 483-485.

18. Tu, P. T. B., \& Tawata, S. (2014). Anti-obesity effects of hispidin and Alpinia zerumbet bioactives in 3T3-L1 adipocytes. Molecules, 19, 16656-16671.

19. Park, I. H., Jeon, S. Y., Lee, H. J., Kim, S. I., \& Song, K. S. (2004). A beta 5-secretase (BACE1) inhibitor hispidin from the mycelial cultures of Phellinus linteus. Planta Medica, 70, 143-146.

20. Martins, S., Mussatto, S. I., Martínez-Avila, G., Montaňez-Saenz, J., Aguilar C. N., \& Teixeira, J. A. (2011). Bioactive phenolic compounds: Production and extraction by solid-state fermentation. A review. Biotechnology Advances, 29, 365-373.

21. Zhai, F. H., Wang, Q., \& Han, J R. (2015). Nutritional components and antioxidant properties of seven kinds of cereals fermented by the basidiomycete Agaricus blazei. Journal of Cereal Science, 65, 202-208.

22. Lim, B. O., Jeon, T. I., Hwang, S. G., Moon, J. H., \& Park, D. K. (2005). Phellinus linteus grown on germinated brown rice suppresses IgE production by the modulation of Th1/Th2 balance in murine mesenteric lymph node lymphocytes. Biotechnology Letters, 27, 613-617. 
23. Park, H. J., Han, E. S., Park, D. K., Lee, C., \& Lee, K. W. (2010). An extract of Phellinus linteus grown on germinated brown rice inhibits inflammation markers in RAW264.7 macrophages by suppressing inflammatory cytokines, chemokines, and mediators and up-regulating antioxidant activity. Journal of Medicinal Food, 13, 1468-1477.

24. Park, H. J. (2015). Phellinus linteus grown on germinated brown rice suppress metastasis and induce apoptosis of colon cancer cells by suppressing NF-KB and Wnt/ $\beta$-catenin signaling pathways. Journal of Functional Foods, 14, 289-298.

25. Seitz, L. M., Sauer, D. B., Burroughs, R. M., Mohr, H. E., \& Hubbard, J. D. (1979). Ergosterol as a measure of fungal growth. Phytopathology, 69, 1202-1203.

26. Matcham, S., Jordan, B., \& Wood, D. (1985). Estimation of fungal biomass in a solid substrate by three independent methods. Applied Microbiology and Biotechnology, 21, 108-112.

27. Lee, I. K., \& Yun, B. S. (2006). Hispidin analogs from the mushroom Inonotus xeranticus and their free radical scavenging activity. Bioorganic \& Medicinal Chemistry Letters, 16, 2376-2379.

28. Lee, I. K., \& Yun, B. S. (2007). Highly oxygenated and unsaturated metabolites providing a diversity of hispidin class antioxidants in the medicinal mushrooms Inonotus and Phellinus. Bioorganic \& Medicinal Chemistry, 15, 3309-3314.

29. Anouar, E. H., Shah, S. A. A., Hassan, N. B., Moussaoui, N. E., Ahmad, R., Zulkefeli, M., \& Weber, J.F. (2014). Antioxidant activity of hispidin oligomers from medicinal fungi: A DFT study. Molecules, 19, 3489-3507.

30. Liang, C. H., Syu, J. L., \& Mau, J. L. (2009). Antioxidant properties of solid-state fermented adlay and rice by Phellinus linteus. Food Chemistry, 116, 841-845.

\section{Tables}

Table 1 Tested strains and their symbols in this study 


\begin{tabular}{|c|c|c|}
\hline Strain & Symbol & Source \\
\hline $\begin{array}{l}\text { Phellinus apiahynus } \\
\text { BCRC } 35468\end{array}$ & 35468 & $\begin{array}{l}\text { Bioresource Collection and Research Center (BCRC), Food } \\
\text { Industry Research and Development Institute }\end{array}$ \\
\hline $\begin{array}{l}\text { Phellinus igniarius BCRC } \\
35308\end{array}$ & 35308 & BCRC, Food Industry Research and Development Institute \\
\hline $\begin{array}{l}\text { Phellinus pachyphloeus } \\
\text { BCRC MU30300 }\end{array}$ & 30300 & BCRC, Food Industry Research and Development Institute \\
\hline $\begin{array}{l}\text { Phellinus sp. BCRC } \\
36900\end{array}$ & 36900 & BCRC, Food Industry Research and Development Institute \\
\hline Phellinus sp. L & L & Preservation in our laboratory \\
\hline Phellinus linteus 03 & 03 & Preservation in our laboratory \\
\hline Phellinus linteus 04 & 04 & Preservation in our laboratory \\
\hline Phellinus linteus 06 & 06 & Preservation in our laboratory \\
\hline Phellinus linteus Youhao & Youhao & Preservation in our laboratory \\
\hline Phellinus linteus Wang & Wang & Preservation in our laboratory \\
\hline Phellinus linteus 85105 & 85105 & Preservation in our laboratory \\
\hline $\begin{array}{l}\text { Phellinus linteus } \\
\text { Zhejiang }\end{array}$ & Zhejiang & Preservation in our laboratory \\
\hline
\end{tabular}

Table 2 Total contents of hispidin in brown rice medium for different Phellinus strains at their highest hispidin production time 


\section{Total content of hispidin ${ }^{\mathrm{a}}(\mathrm{mg} / \mathrm{kg}) \quad$ Fermentation time (week)}

\begin{tabular}{lll} 
Strain & & \\
\hline 35308 & $2.45 \pm 0.02$ & 8 \\
\hline 35468 & $0.00 \pm 0.00$ & 8 \\
\hline 36900 & $0.00 \pm 0.00$ & 8 \\
\hline 30300 & $0.00 \pm 0.00$ & 8 \\
\hline L & $63.37 \pm 3.36$ & 5 \\
\hline 03 & $69.65 \pm 1.14$ & 6 \\
\hline 04 & $70.05 \pm 1.62$ & 6 \\
\hline 06 & $22.60 \pm 0.16$ & 6 \\
\hline Youhao & $4.26 \pm 0.05$ & 8 \\
\hline Wang & $3.93 \pm 0.03$ & 8 \\
\hline 85105 & $12.63 \pm 0.12$ & 6 \\
\hline Zhejiang & $38.19 \pm 0.15$ & 6
\end{tabular}

a Total content of hispidin: biomass [mycelia $(\mathrm{g}) /$ medium $(\mathrm{kg})$ ] $\times$ hispidin yield [hispidin content $(\mathrm{mg}) /$ mycelia (g)]

Table 3 Total contents of hispidin in different grain media for Phellinus linteus 04 at their highest hispidin production time 


\section{Total content of hispidin ${ }^{\mathrm{a}}(\mathrm{mg} / \mathrm{kg}) \quad$ Fermentation time (week)}

\begin{tabular}{lll} 
Medium & & \\
\hline Brown rice & $37.32 \pm 0.08$ & 6 \\
\hline Millet & $6.24 \pm 0.01$ & 6 \\
\hline Black rice & $90.43 \pm 0.08$ & 6 \\
\hline Wheat & $24.92 \pm 0.01$ & 6 \\
\hline Buckwheat & $30.85 \pm 0.03$ & 7 \\
\hline Pearl barley & $199.76 \pm 1.04$ & 6 \\
\hline Oat & $31.64 \pm 0.13$ & 5 \\
\hline Adlay & $147.28 \pm 1.64$ & 7
\end{tabular}

${ }^{a}$ Total content of hispidin: biomass [mycelia $(\mathrm{g}) /$ medium $(\mathrm{kg})$ ] $\times$ hispidin content [hispidin yield (mg)/ mycelia (g)]

\section{Figures}




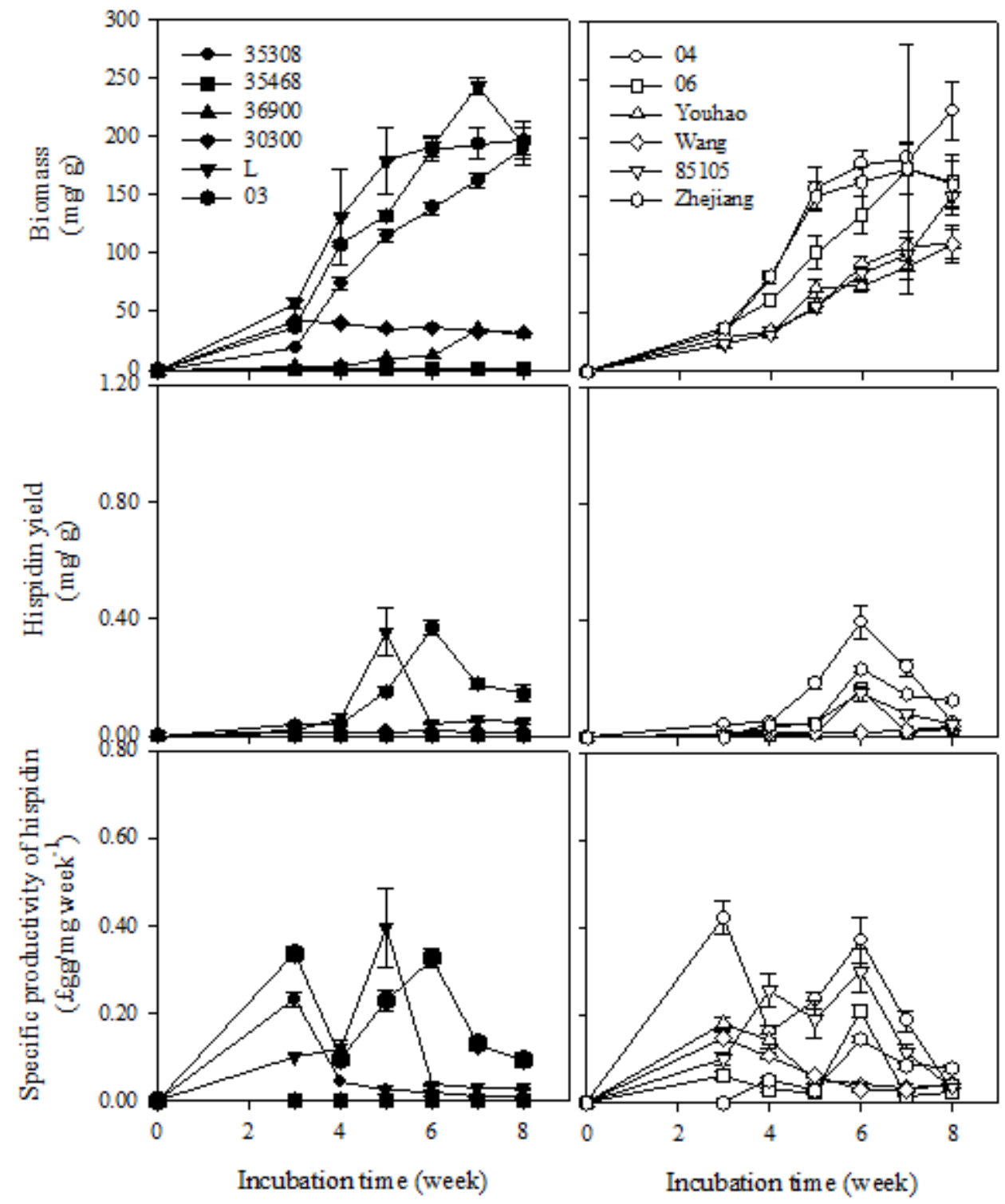

Figure 1

Hispidin production in fermented brown rice by different Phellinus strains during fermentation. Liquid spawn conditions and grain medium were as follows. Liquid spawn culture medium: potato dextrose broth; liquid spawn age: 1 week; water content of grain medium: 55\%; spawn rate: $10 \%$ (v/w); grain medium: brown rice. 


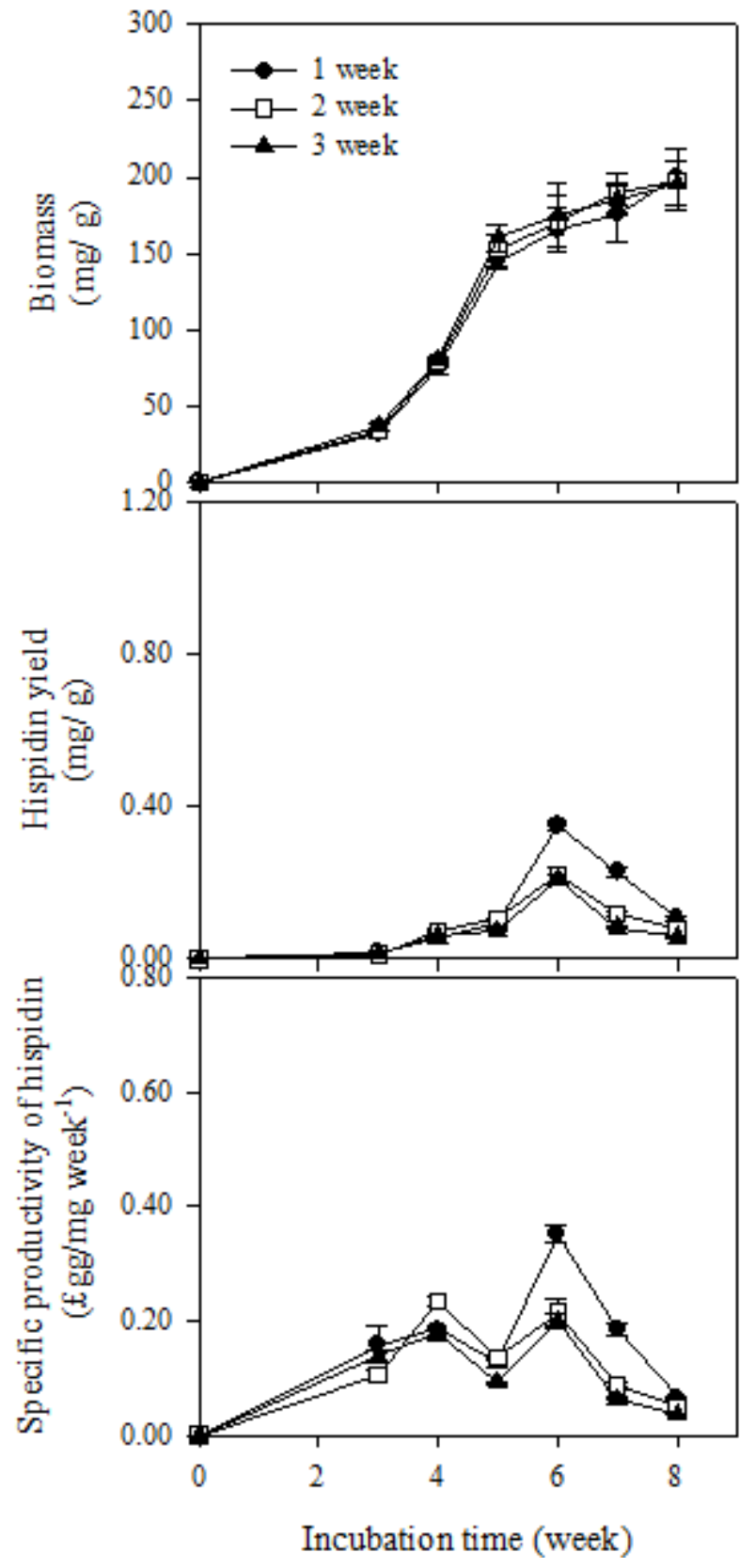

Figure 2

Effect of three different spawn ages influenced mycelial growth and hispidin production in brown rice fermented by Phellinus linteus 04 during fermentation. Liquid spawn conditions and grain medium were as follows. Liquid spawn culture medium: potato dextrose broth; water content of grain medium: $55 \%$; spawn rate: $10 \%(\mathrm{v} / \mathrm{w})$; grain medium: brown rice. 


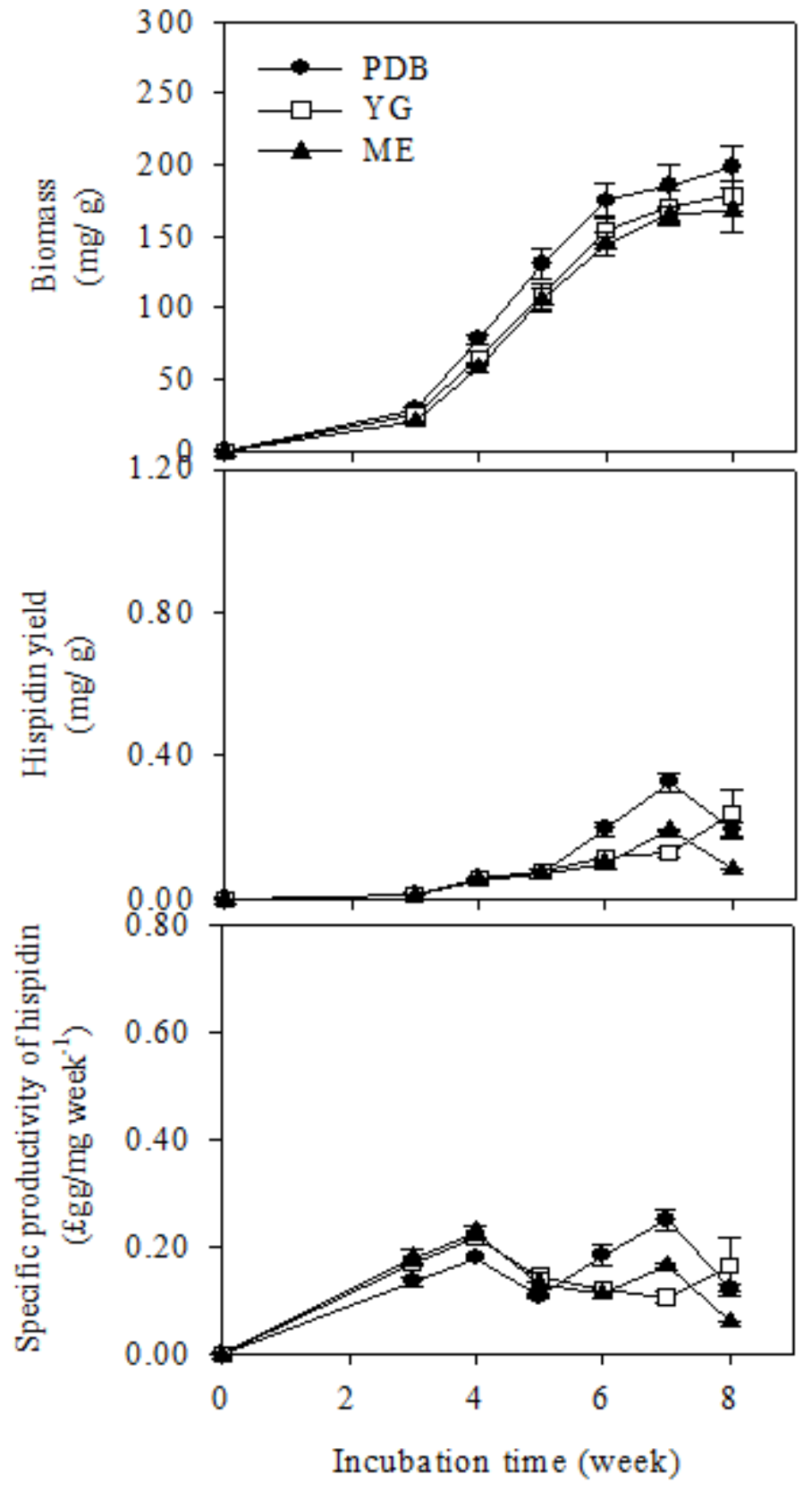

Figure 3

Effect of three different liquid spawn culture media influenced mycelial growth and hispidin production in brown rice fermented by Phellinus linteus 04 during fermentation. Liquid spawn conditions and grain medium were as follows. Liquid spawn age: 1 week; water content of grain medium: 55\%; spawn rate: 10 $\%(\mathrm{v} / \mathrm{w})$; grain medium: brown rice. 


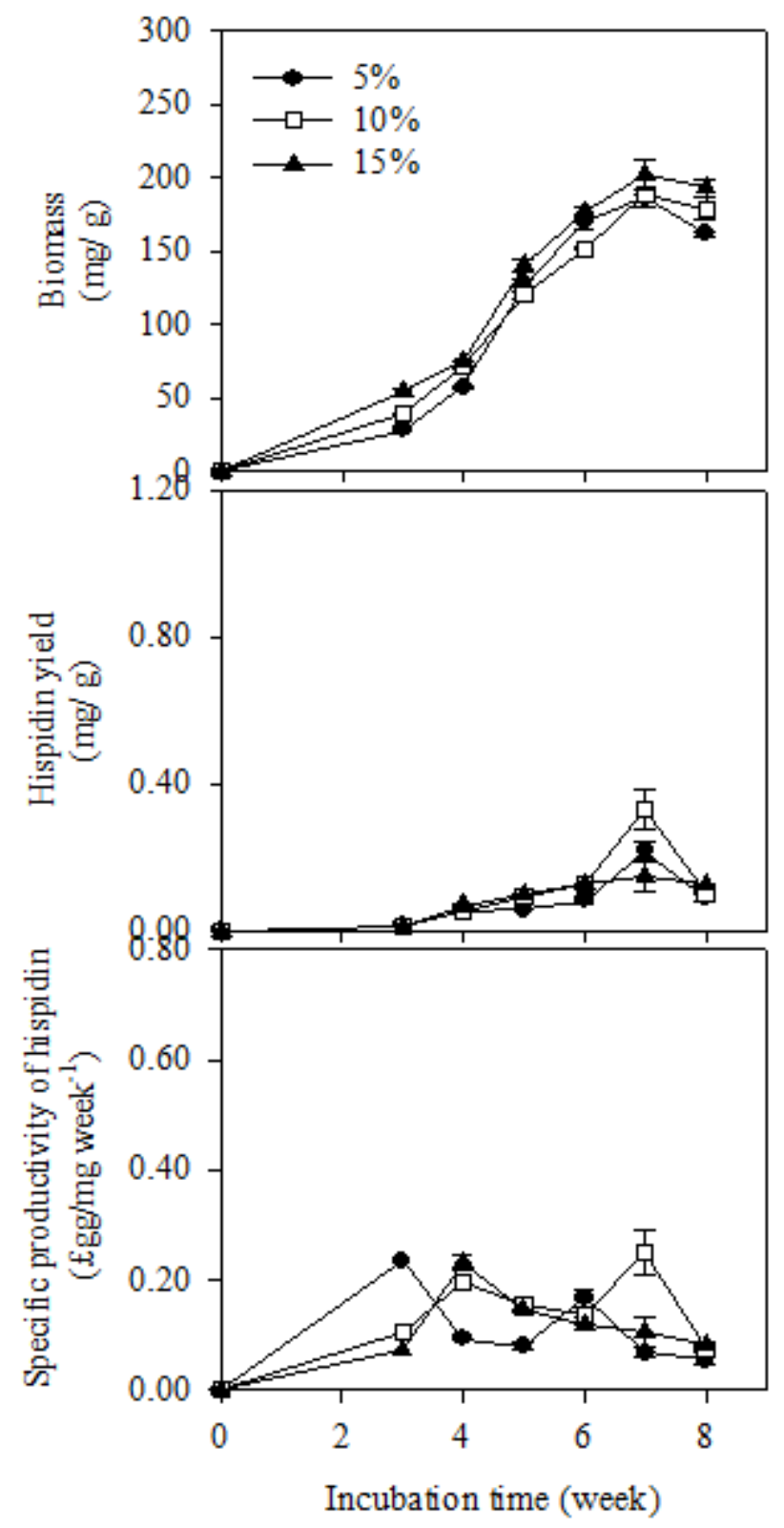

Figure 4

Effect of three different liquid spawn inoculum rates influenced mycelial growth and hispidin production in brown rice fermented by Phellinus linteus 04 during fermentation. Liquid spawn conditions and grain medium were as follows. Liquid spawn culture medium: potato dextrose broth; liquid spawn age: 1 week; water content of grain medium: 55\%; grain medium: brown rice. 

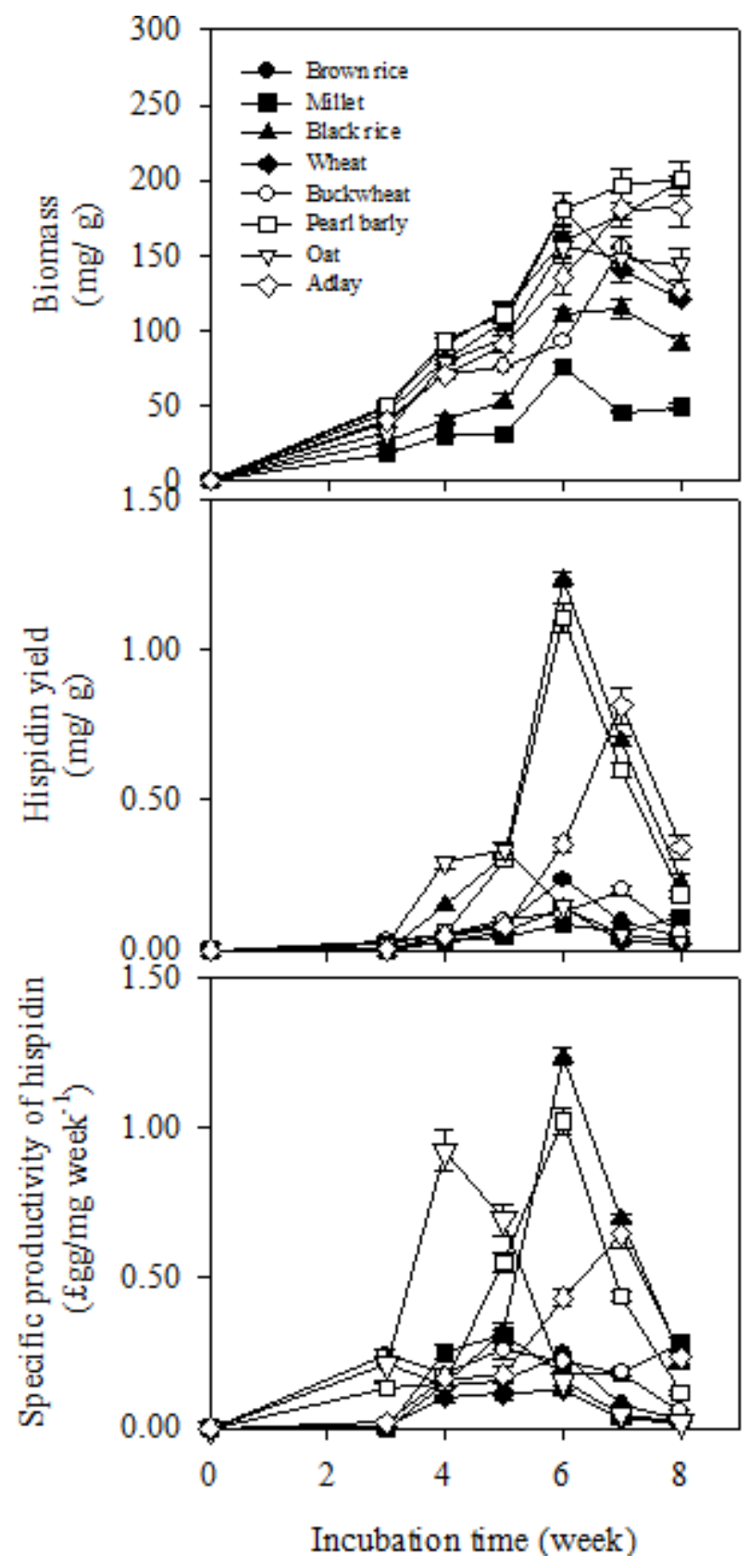

Figure 5

Effect of different grain media on mycelial growth and hispidin production fermented by Phellinus linteus 04 during fermentation. Liquid spawn conditions were as follows. Liquid spawn culture medium: potato dextrose broth; liquid spawn age: 1 week; water content of grain medium: 55\%; spawn rate: $10 \%(\mathrm{v} / \mathrm{w})$. 